\title{
An Overview of Virulence-Associated Factors of Gram-Negative Fish Pathogenic Bacteria
}

\author{
Jessica Méndez, Pilar Reimundo, David Pérez-Pascual, \\ Roberto Navais, Esther Gómez, Desirée Cascales and José A. Guijarro \\ Department of Microbiology, IUBA, \\ University of Oviedo, Oviedo, Asturias \\ Spain
}

\section{Introduction}

Bacterial diseases are among the most important causes of losses among fish stocks in the aquaculture industry, affecting the economic development of the sector in many countries. The ability of bacteria to cause disease depends to a large extent on the expression of virulence factors, which help them to invade the host, produce pathological effects and evade host defences. The study of these factors is essential for the development of new immunoprophylactic and chemotherapeutic reagents to fight the bacterial infections, since the development of antibiotic resistance by bacteria has led to these diseases becoming one of the major problems in the sector. In the last decade, the application of in vivo and in vitro molecular techniques to fish pathogenic bacteria, together with the availability of adequate models for studying the disease, have allowed the discovery and characterization of novel virulence determinants, as well as a deeper insight into well-known pathogenic mechanisms. In reference to bacterial diseases, Gram-negative bacteria have long been recognized as one of the main problems in the aquaculture industry. They can cause systemic infections in which they invade the fish and damage internal organs or can cause external infections affecting the gills or causing fin rot and body ulcers. This review describes current understanding of the virulence factors shown to be involved in the virulence of Gram-negative bacteria causing disease in fish.

\section{Bacterial adherence and colonization}

\subsection{Adhesins}

Bacterial adherence to the host may involve either specific interactions between a receptor and a ligand or hydrophobic interactions. The receptors are usually specific carbohydrate or peptide residues on the eucaryotic cell surface and the ligands called adhesins are bacterialsurface proteins or polysaccharides.

Many pathogenic Gram-negative bacteria display long adhesive fibers, called type IV pili, in order to mediate cellular attachment to host tissue receptors. Pili are also involved in several other bacterial processes, including bacterial auto-aggregation, target tissue specificity and natural competence for DNA uptake. 
The fish pathogenic bacterium Aeromonas salmonicida subsp. salmonicida contains in its genome a complete set of genes for two type IV pilus systems, Tap and Flp (Boyd et al., 2008). In vivo experiments in rainbow trout (Oncorhynchus mykiss) showed that the Tap pilus contributes moderately to virulence. A tapA mutant constructed by allelic exchange was found to be slightly less pathogenic than wild type when delivered by intraperitoneal injection (Masada et al., 2002). Boyd et al. (2008) showed that the Tap pilus also made a moderate contribution to virulence in Atlantic salmon (Salmo salar), while the Flp pilus made little or no contribution. In addition to type IV pili, A. salmonicida has also a type I or Fim pilus system (similar to Pap fimbriae of Escherichia coli) encoded by several genes clustered into an operon. When this operon was deleted in A. salmonicida A449, the virulence of this strain was not affected in direct live challenges of Atlantic salmon. However, an ex vivo adherence and invasion assay using freshly excised salmon gastrointestinal tract showed that, compared to the parental strain, the ability of a fim mutant strain to adhere to the salmon gastrointestinal tract was reduced but, once adhered, its capacity to invade was unaffected (Dacanay et al., 2010).

In A. salmonicida, the S-layer also acts as an adhesin promoting high levels of adherence to non-phagocytic fish cell lines (Garduño et al., 2000). The capsular polysaccharide is involved in the ability of A. salmonicida and Aeromonas hydrophila, the leading cause of fatal hemorrhagic septicemia in rainbow trout, to both adhere to and invade fish cell lines, being an important factor for intracellular invasion (Merino et al., 1996, 1997a). The capsule also plays an important role in the pathogenicity of Photobacterium damselae subsp. piscicida (formerly Pasteurella piscicida), the etiological agent of pasteurellosis in fish. The induction of its expression increased the degree of virulence for fish of the non-pathogenic strains and conferred resistance to serum killing (Magariños et al., 1996).

\subsection{Motility}

Bacteria have developed at least six different types of motility (Henrichsen, 1972). The evolutionary maintenance of motility, despite its high energetic cost, indicates its importance for the survival of bacteria in changing milieus. Additionally, motility is considered essential during host tissue colonization in pathogenic bacteria.

For instance, the fish pathogen Listonella anguillarum (formerly Vibrio anguillarum), the causal agent of vibriosis, required the presence of the flagellum to produce the disease when rainbow trout were infected by immersion in bacteria-containing water. However, this appendix and the bacteria's resulting motility were not required for pathogenicity following intraperitoneal injection (O'Toole et al., 1996). Ormonde et al. (2000) suggested that active motility is essential for this bacterium to enter the fish host, maybe in a process driven by a fish skin and intestinal mucus chemotactic response. In this work, the authors created a strain with an intact but paralyzed flagellum by disruption of the mot $Y$ gene, a flagellar motor gene. The virulence of the mot $Y$ mutant was 750 -fold lower than that of the wild type strain when the bacterium was supplied by immersion, using rainbow trout as the infection model; however, no loss in virulence was seen when the mot $Y$ mutant was injected intraperitoneally. Taken together, these results suggest that motility and not the flagellin proteins are required for L. anguillarum to invade rainbow trout successfully (Ormonde et al., 2000). In A. hydrophila, the motility is important for the adhesion and invasion by the bacteria of fish cell lines, as was demonstrated by Merino et al. (1997b). Gavín et al. (2002) 
concluded that the lateral flagella are mainly responsible for the adhesion process in this species and also for its ability to form biofilm. However, in the case of Yersinia ruckeri, the causal agent of yersiniosis, a non-motile biogroup identified as Y. ruckeri serovar I biotype 2 has been described, which is able to cause the disease in rainbow trout (Austin et al., 2003; Fouz et al., 2006). In fact, Evenhuis et al. (2009) have demonstrated that the lack of the flagellum and flagellar secretion machinery do not affect $Y$. ruckeri virulence.

In general, there are few cases establishing a direct relation between fish pathogenic bacteria motility and disease development. The reason may be that mutations in motility-related genes usually involve pleiotropic phenotypes. Therefore, it is difficult to ascribe the absence of virulence exclusively to the lack of motility. However, all authors recognise the importance of motility for host tissue colonization during the first stages of the infection.

\section{Growth and invasion}

\subsection{Iron acquisition}

Iron is an essential element for most bacteria due to its participation as a cofactor in numerous biochemical cellular processes. Thus, bacteria have developed high-affinity irontransport systems that are considered to be important factors in pathogenicity. Many bacteria are able to synthesize low molecular mass molecules, or siderophores, which bind ferric iron (Ratledge \& Dover, 2000; Ratledge, 2007). These iron compounds are then recognized by specific outer membrane receptors and introduced into the cell by an energytransduction complex named TonB system (Andrews et al., 2003; Ratledge, 2007; Ratledge \& Dover, 2000; Wandersman \& Delepelaire, 2004). A second iron-acquisition mechanism is based on a direct interaction between the host iron-containing proteins transferrin, lactoferrin and ferritin and specific receptors on the bacterial cell surface (Butler, 2003; Ratledge, 2007). Some pathogenic bacteria are also able to acquire iron from free haem or haem proteins, such as hemoglobin or hemopexin within host tissues (Genco \& Dixon, 2001; Tong \& Guo, 2009).

Evidence for the role of different iron scavenging mechanisms in promoting Gram-negative bacterial infections within fish hosts have been reported in literature on several occasions. For example, the isolation and further analysis of a mutant showing impaired growth under iron-limited conditions using a Tn4351-mutagenesis system led to the identification of a TonB system which includes ExbB, ExbD1, ExbD2 and TonB proteins in Flavobacterium psychrophilum, the causative agent of cold water disease in salmonids (Álvarez et al., 2008). Moreover, in vivo assays conducted in rainbow trout fry determined that the ExbD2 protein plays an important role in virulence of $F$. psychrophilum, since the exbD2 mutant strain was approximately 450 -fold attenuated compared to the wild strain and conferred a high level of protection after vaccination (Álvarez et al., 2008).

Two different TonB systems, TonB1 and TonB2, were identified and characterized in the pathogen Vibrio algynoliticus, which causes vibriosis in marine fish (Wang et al., 2008). Construction and further analysis of mutants in these systems led to the conclusion that they are involved in iron uptake from ferrichrome and vibrioferrin and that they are also essential for virulence, since the corresponding mutant strains showed an 11 to 25-fold increase in $\mathrm{LD}_{50}$ value in zebra fish (Danio rerio) in comparison to that of the wild type strain (Wang et al., 2008). Besides, the TonB1 gene cluster was shown to specifically contribute to 
haemin and haemoglobin utilization in this fish pathogen (Wang et al., 2008). In the same way, two different iron-regulated TonB mechanisms were identified in L. anguillarum (Stork et al., 2004). The analysis of these systems revealed that TonB2 protein but not TonB1 is involved in the transport of the siderophores anguibactin and enterobactin and that TonB2 protein is essential for virulence of L. anguillarum, since the $\mathrm{LD}_{50}$ value for the tonB2 mutant strain was more than 100-fold higher than that of the parental strain (Stork et al., 2004).

Following suppressive subtraction hybridization experiments, the existence of a siderophore biosynthesis gene cluster in P. damselae subsp. piscicida was reported (Osorio et al., 2006). Insertional mutation of an irp 1 gene included within this cluster, which codes for a putative non-ribosomal peptide synthetase, led to impaired growth under iron-limited conditions, loss of siderophore production and a 100-fold decrease in degree of virulence in turbot fingerlings (Scophthalmus maximus) (Osorio et al., 2006).

The application of an in vivo expression technology system to the study of the fish pathogen $Y$. ruckeri permitted the identification of, among others, four clones involved in the biosynthesis and transport of a cathecol siderophore named ruckerbactin (Fernández et al., 2004). An isogenic mutant in rucC (involved in ruckerbactin biosynthesis) was conducted and it was demonstrated that this strain was impaired for growth under iron-depleted conditions with respect to the wild type strain. Moreover, in vivo assays carried out in rainbow trout indicated that the $\mathrm{LD}_{50}$ value for the rucC mutant was 100 -fold higher than that of the wild type strain (Fernández et al., 2004).

The iron-uptake processes and their importance as determinants in pathogenicity have been widely studied in L. anguillarum. In 1980, it was demonstrated in in vivo challenge experiments on juvenile Coho salmon that heat-mediated curation of a $65 \mathrm{~Kb}$ plasmid of this bacterium, named pJM1, was correlated with an attenuation of virulence of about 3 logarithms (Crosa et al., 1980). The pJM1-type plasmids encode the genes responsible for the biosynthesis and transport of the siderophore anguibactin, an iron-sequestering system that represents a major virulence factor in L. anguillarum (Crosa, 1989; Lemos et al., 1988). One of these plasmidencoded genes, $a n g R$, is involved in the regulation of both the expression of the iron transport genes fatDCBA and the production of the siderophore anguibactin (Chen et al., 1996; Salinas et al., 1989). Construction and subsequent analysis of site-directed $a n g R$ mutants and deletion derivatives indicated that an intact AngR protein is required for full virulence and anguibactin production in L. anguillarum but not for regulation of iron-transport gene expression (Wertheimer et al., 1999). Virulence tests carried out on juvenile trout showed that the angR mutation results in a dramatic attenuation of virulence of about five logarithms in $L$. anguillarum (Wertheimer et al., 1999). Additional iron uptake systems have been found in this bacterium. For example, isolation of mutants defective in haem utilization led to the identification of the gene $h u v A$, which encodes an iron-regulated outer membrane protein involved in a specific haem uptake mechanism (Mazoy et al., 2003). The analysis of the huvA mutant strain revealed inability to grow in the presence of haem as the sole iron source as well as a decrease in the degree of virulence for turbot fingerlings in experimental infections in which fish were previously overloaded with haemin (Mazoy et al., 2003).

It has been clearly demonstrated that the ability of pathogenic bacteria to scavenge iron from the fish host is of vital importance to the outcome of the disease. Thus, iron acquisition mechanisms should be deeply studied in bacterial fish pathogens and may be considered as optimal targets for the development of new antimicrobial agents in aquaculture. 


\subsection{Extracellular products (ECPs)}

Separation of the extracellular products (ECPs) secreted by bacteria from the cell fraction has been a common strategy for studying the virulence factors of fish-pathogenic bacteria. The analysis of the pathological effects of their different components on fish can give us substantial information about host-pathogen interactions. Among these components, molecules with different activities such as haemolytic, cytolytic, proteolytic and lipolytic, etc. have been identified.

ECPs and extracellular proteases have been well studied in the genus Aeromonas and there are numerous reports showing their implication in the virulence of this pathogen. The species A. hydrophila produces extracellular substances that are capable of causing pathological effects when injected into rainbow trout and tilapia (Tilapia nilotica) (Allan \& Stevenson, 1981; Khalil \& Mansour, 1997; Santos et al., 1988). Allan and Stevenson (1981) showed that the in vivo effect observed in rainbow trout, as well as the proteolytic and haemolytic activities, were lost when ECPs were heated. These authors also suggested haemolytic activity as a significant lethality factor.

The ECPs of A. salmonicida seem to play a relevant role in the pathogenesis of fish furunculosis. Ellis et al. (1981) showed that all the lesions associated with this disease were reproduced when ECPs were injected intraperitoneally or intramuscularly into rainbow trout. A few years later, it was indicated that the presence of protease and haemolysin activities in the ECPs of $A$. salmonicida was correlated with the development of lesions but not with the lethal toxicity of the ECPs in rainbow trout. Thus, an unidentified component of ECP was responsible for killing fish (Ellis et al., 1988). Concerning the two major extracellular enzymes of A. salmonicida, glycerophospholipid: cholesterol acyltransferase (GCAT) and a serine protease (AspA), it has been surprisingly revealed that no major decrease in virulence in Atlantic salmon occurred when their encoding genes were mutated (Vipond et al., 1998).

The role in virulence of the activities present in ECPs within the family Vibrionaceae has also been closely studied. In L. anguillarum, different exoenzymes (i.e. haemolysins, cytotoxins, and dermatotoxins) can contribute to the development of infections (Kodama et al., 1984). Nevertheless, metalloproteases and undetermined low molecular weight substances are the main toxins responsible for the lethality of their ECPs (Toranzo \& Barja, 1993). This was illustrated with the work of Santos et al. (1991) which showed that, although all L. anguillarum isolates tested were virulent for trout, salmon and turbot, rainbow trout was the most susceptible fish species to experimentally induced vibriosis. In contrast, the ECPs (with proteolytic, haemolytic, cytotoxic activities and permeability factors) exhibited similar lethal doses for turbot, salmon and trout. Therefore, differences in susceptibility to vibriosis were not completely due to a differential sensitivity of fish to the extracellular products of this bacterium. In L. anguillarum, a membrane-bound lytic murein transglycosylase D (mltD) mutant was generated and its extracellular protease activity decreased markedly together with a total loss of haemolytic activity compared with the wild type strain (Xu et al., 2011). The MltD protein was characterized and it showed haemolytic, phospholipase, gelatinase and diastase activities. Surprisingly, virulence of the $m l t D$ mutant was enhanced compared with that of the wild type when it was inoculated intraperitoneally into zebra fish. This could be partially explained by the hypothesis that peptidoglycan (PG) fragments, released during growth, can contribute to the pathogenesis of multiple bacterial infections (Xu et al., 2011). 
With regards to other Vibrionaceae species, it has been demonstrated that the ECPs from all the strains of $P$. damselae sp. damselae are strongly lethal for fish (Fouz et al., 1993). These ECP samples possessed low proteolytic activity but remarkable phospholipase and haemolytic activities for turbot red blood cells and were cytotoxic for fish. Finally, a correlation could be established between the levels of enzymatic and cytotoxic activities of ECPs and the degree of virulence for fish (Fouz et al., 1993). Additionally, it was shown that the ECPs from 16 strains of $P$. damselae subsp. damselae that were strongly lethal for redbanded seabream (Pagrus auriga) exhibited lipase, phospholipase and esterase-lipase activities among others (Labella et al., 2010). They also displayed a strong cytotoxic effect on four fish cell lines, although this effect disappeared when ECPs were heated at $100^{\circ} \mathrm{C}$. The virulence of the strains tested could not be related to the haemolytic activity or to the production of the toxin damselysin. Therefore, another unknown type of toxin could play an important role in the virulence mechanisms of this bacterium (Labella et al., 2010).

There are also many works with other Gram-negative bacteria whose ECPs have been tested on their hosts. As described by Romalde \& Toranzo (1993), ECPs (including proteolytic haemolytic, cytotoxic, and lipolytic activities) could play a role in the pathogenicity of $Y$. ruckeri because when injected into fish they lead to the appearance of symptoms related to yersiniosis. The same occurs with F. psychrophilum. A crude extracellular preparation (CEP) from a strain of this bacterium was capable of causing serious muscle necrosis in rainbow trout after intramuscular injection. The CEP degraded gelatin, but the addition of protease inhibitors to the CEP simultaneously terminated its ability to degrade this protein in vitro and to produce muscle necrosis in rainbow trout. Both effects were restored following the addition of zinc chloride to the protease inhibitor-treated CEP, suggesting that this strain of F. psychrophilum secretes a protein complex with zinc metalloprotease-like activity (Ostland et al., 2000).

In relation to the degradation of non-proteinaceous components from the extracellular matrix of fish tissue, the activity of a chondroitin AC lyase present in Flavobacterium columnare could be the cause of the necrotic lesions characteristic of the columnaris disease (Suomalainen et al., 2006).

\subsubsection{Extracellular proteases}

Production of extracellular proteolytic enzymes is a property shared by non-pathogenic and pathogenic microorganisms. These enzymes are indispensable factors in their life cycles and may be lethal to the host when produced by pathogenic bacteria (Miyoshi \& Shinoda, 2000). The role of proteases in pathogenesis is not clear, but it seems that they are involved in colonization and invasion during host-pathogen interaction, apart from providing nutrients for the microorganism.

This idea is also strengthened by the findings of a wide variety of studies, such as that on Moritella viscosa, which causes winter ulcer disease in salmonids (Bjornsdottir et al., 2009). The metallopeptidase MvP1 of this pathogen caused extensive tissue necrosis and haemorrhages at the site of injection but was non-lethal to salmon at concentrations up to $0.22 \mu \mathrm{g} / \mathrm{g}$ fish. The authors suggested that MvP1 could aid in the invasion and dissemination of the bacterium in the host by causing tissue destruction (Bjornsdottir et al., 2009). The same function is attributed to the protease Yrp1 of Y. ruckeri, included within the serralysin metalloendopeptidase subfamily. The mutation of the yrp 1 gene caused the loss of 
the proteolytic activity as well as attenuation in virulence when the mutant was injected intraperitoneally into rainbow trout (Fernández et al., 2002).

Additional reports relating to the activity of extracellular metalloproteases in virulence can be found. The participation of an extracellular zinc metalloprotease in the first steps of the infectious process by promoting invasion is suggested in L. anguillarum. Norqvist et al. (1990) isolated a mutant with a low level of protease activity. This mutant behaved also as an invasiveness-defective strain. When compared with wild type strain, this mutant had a 1,000-fold higher $\mathrm{LD}_{50}$ value after immersion infection of rainbow trout. In the work of Yang et al. (2007), it is also proposed that an extracellular zinc metalloprotease, EmpA, is a putative virulence factor of the fish pathogen L. anguillarum.

Proteolytic enzymes may play an important role in invasiveness and establishment of infection by overcoming initial host defences and by providing nutrients for cell proliferation, as has been suggested for Aeromonas spp. (Leung \& Stevenson, 1988). The first report in which the mutation of an extracellular protease of $A$. hydrophila was related to a decrease in virulence was the work of Cascón et al. (2000). The protease (AhpB) hydrolyzed casein and elastin and showed a high sequence similarity to other metalloproteases. The mutation of $a h p B$ resulted in 100-fold attenuation in virulence for rainbow trout. Indeed, in local infections proteases can cause necrotic or haemorrhagic tissue damage through digestion of structural components of the ground substance and form oedematous lesions through generation of an inflammatory response (Miyoshi \& Shinoda, 2000). As Abolghait et al. (2010) indicated, intramuscular infection of goldfish (Carassius auratus) with wild type A. hydrophila led to the development of a characteristic large ulcer at the injection site while the PepO (a thermoregulated outer membrane M13 family zinc endopeptidase) deficient mutant strain lost its ulcerogenic property in vivo. However, this mutant strain caused a higher mortality in goldfish than the wild type $A$. hydrophila. This paradox could be partially clarified by the evidence that pepO-mutagenesis changed the extracellular proteome, suggesting that PepO may regulate the secretion and/or the expression of some of A. hydrophila virulence factors present in ECPs. What is more, metalloproteases from $A$. hydrophila could have a more harmful effect and even be lethal to the host. Extensive haemorrhages in the abdominal cavity were caused after injection with the protease obtained from the culture filtrate of this pathogen (Kanai \& Wakabayashi, 1984).

Combining protease isolation and gene interruption in A. salmonicida, as early as 1985, Sakai showed that a protease-deficient mutant (NTG-1) lost its virulence and proteolytic activity in Sockeye salmon (Oncorhynchus nerka) and rainbow trout. In addition, the activity of an extracellular metallo-caseinase, AsaP1, was linked with lethal toxicity and a strong pathogenic effect (Gunnlaugsdóttir \& Gudmundsdóttir, 1997) in A. salmonicida subsp. achromogenes for Atlantic salmon fingerlings. Besides, the lethal dose of an AsaP1-defective strain was 10-fold higher in Artic charr (Salvelinus alpinus) and 5-fold higher in Atlantic salmon than that of the wild type strain (Arnadottir et al., 2009).

However, the involvement of extracellular metalloproteases in the virulence of fish pathogenic bacteria is not a general rule, given that the metalloprotease Vvp of $V$. vulnificus, is not an essential lesion factor. Thus, when the ECPs from a Vvp-defective mutant were injected into fish, similar lesions to those caused by the wild type strain appeared in eels (Anguilla anguilla) (Valiente et al., 2008). A similar case is that of the Fpp2 proteolytic enzyme 
of F. psychrophilum, which seems not to be involved in the infection process, having a putative nutritional role (Pérez-Pascual et al., 2011). In contrast, according to Zhang et al. (2009b), the AprX of Pseudomonas fluorescens (an extracellular alkaline metalloprotease of the serralysin family) could be involved in the infection process, since an aprX mutant strain exhibited significantly attenuated ability to disseminate and survive within Japanese flounder (Paralichthys olivaceus) blood and tissues. These results, together with the observation that purified recombinant AprX was highly toxic in cultured flounder gill cells, demonstrated that AprX is a virulence factor that contributes to bacterial infection.

\subsubsection{Haemolysins and phospholipases}

Bacterial haemolysins are cytolytic exotoxins, generally considered as important virulence factors. These toxins cause damage to erythrocytes and other cell types, such as leukocytes or neutrophils, by two different models of action which involve a pore-forming protein or a phospholipase enzyme (Rowe \& Welch, 1994). However, their specific mechanism of action as well as their specific contribution to pathogenicity varies in each organism.

There are many reports about bacterial fish pathogens, especially Vibrio species, which possess haemolysin proteins. Thus, Rodkhum et al. (2005) identified four genes, vah2, vah3, vah4 and vah5, which encode four haemolysins in L. anguillarum. These genes were cloned and the corresponding proteins subsequently purified. It was demonstrated that all of them displayed haemolytic activity against erythrocytes of rainbow trout. In addition, construction of a mutant strain for each haemolysin gene and subsequent $\mathrm{LD}_{50}$ assays in rainbow trout determined that the four mutant strains were less virulent than the wild type strain (Rodkhum et al., 2005). Rock \& Nelson (2006) characterized a haemolysin gene cluster that encodes the L. anguillarum haemolysin Vah1, a putative phospholisase (Plp) and a putative lactonizing lipase (LlpA). Mutation in the $p l p$ gene resulted in a significant increase in haemolytic activity but not in virulence. On the contrary, mutations in the vah1 and $l p A$ genes did not affect haemolytic activity. Moreover, the vah1 mutant strain showed virulence attenuation in juvenile Atlantic salmon. The data obtained in this study suggest that plp constitutes a negative regulator of the haemolysin genes vahl and $\operatorname{llp} A$ and that vah1 plays a role in the pathogenicity of this bacterium. A repeat-in-toxin (RTX) gene cluster (rtxACHBDE) related to haemolysis in L. anguillarum was identified by Li et al. (2008) a few years later. Haemolytic-deficient mutant strains were obtained by interrupting vah1 and an $r t x$ gene, leading to the conclusion that the $r t x$ gene cluster represents a new haemolytic mechanism in L. anguillarum. It was proved that Vah1 and RtxA proteins displayed cytotoxic effects on Atlantic salmon kidney cells, whereas the vah1 rtxA double mutant strain lost this cytotoxic activity. Besides, the $r t x A$ mutant strain showed reduced virulence in juvenile Atlantic salmon, suggesting that this gene is a relevant virulence factor for L. anguillarum.

The thermostable direct haemolysin gene $(t d h)$ from $V$. alginolyticus was identified and sequenced by Cai et al. (2007). The encoded protein was expressed and purified in E. coli and it was shown that the Tdh had haemolytic activity and it was toxic for crimson snapper (Lutjanus erythopterus) (Cai et al., 2007). In the same way, Jia et al. (2010) expressed and purified the thermolabile haemolysin (TLH) from $V$. alginolyticus. The experiments carried out with the protein revealed that it had both phospholipase and haemolytic activities against flounder erythrocytes. What is more, toxicity of TLH to zebra fish was demonstrated when injected intraperitoneally, evidencing the importance of this protein in the pathologic process provoked by this bacterium. 
The $V$. harveyi haemolysin gene (vhhA) was overexpressed, purified and characterized by Zhong et al. (2006). Evident phospholipase and haemolytic activities against turbot erythrocytes were determined for this protein. In addition, the protein was proved cytotoxic for flounder gill cells as well as lethal for flounder (Zhong et al., 2006). Later, Sun et al. (2007) carried out the construction of a vhhA site-directed mutant strain. It was observed that this mutant strain exhibited loss of haemolytic and phospholipase activities, together with a complete lack of virulence for turbot (Scophthalmus maximus). A haemolysin gene cluster, which encodes an YhlB haemolysin activation protein and a YhlA haemolysin, was identified in Y. ruckeri by Fernández et al. (2007). Insertional mutant strains of the two proteins were constructed and it was concluded that both mutant strains exhibit reduced haemolytic activity relative to that of the parental strain. What is more, $\mathrm{LD}_{50}$ assays carried out in rainbow trout determined that $y h l A$ and $y h l B$ mutant strains showed a 10 -fold and 100 -fold decrease in virulence respectively, which clearly implicated this system in the virulence of the bacterium (Fernández et al., 2007).

The mutation of the esrB gene of Edwardsiella tarda, part of the two-component system EsrAEsrB, resulted in severe attenuation in virulence but this was accompanied by significantly enhanced haemolytic activity and cell-invasion capability (Wang et al., 2010b). The authors observed that a haemolysis-associated protein, EthA, was up-regulated in this mutant strain. The construction and subsequent analysis of an ethA mutant strain determined that it exhibited decreased capacities of internalization into epithelial papilloma of carp cells. Nevertheless, no significant differences were recorded between the $\mathrm{LD}_{50}$ values obtained in zebra fish and Japanese flounder for the mutant and the wild type strains, thus questioning its contribution to lethality in the fish host (Wang et al., 2010b).

Several proteins have been shown to be involved in the haemolytic process in A. hydrophila. Thus, Li et al. (2011) evaluated the relationship between the presence of the aerolysin (aerA), cytotoxic enterotoxin (alt) and serine protease (ahp) genes, and virulence of A. hydrophila isolates in zebra fish. The authors conclude that the aerA+alt+ahp+ isolates were more virulent to zebra fish than other single or two-virulence-factor combination strains. Apart from haemolysins, phospholipases constitute other important membrane-active agents in many pathogenic bacteria (Bai et al., 2010). In A. hydrophila AH-3, the plc gene codes for a 65$\mathrm{kDa}$ protein involved in phospholipase $\mathrm{C}$ activity. An insertion mutant in this gene showed a 10 -fold increase in its $\mathrm{LD}_{50}$ in rainbow trout and mice, suggesting that Plc protein is a virulence factor (Merino et al., 1999). Furthermore, Plc is also a cytotoxic factor against epithelioma papulosum of carp (Cyprinus carpium) monolayers and slightly haemolytic for rainbow trout erythrocytes (Merino et al., 1999).

As a conclusion, it has been clearly demonstrated that ECPs from Gram-negative fishpathogenic bacteria have a variety of damaging factors as haemolysins, cytotoxins, proteases, phospholipases, etc. which result in the appearance of symptoms of the disease and even more frequently in a toxic effect causing the death of fish.

\subsection{Protein secretion systems}

Protein secretion is involved in different processes in the bacterial life cycle, including organelle biogenesis, nutrient acquisition and virulence-factor expression. In Gram-negative bacteria, where secretion involves translocation across inner and outer membranes, up to six 
different secretion pathways for protein export to the extracellular environment have been identified. Some secreted proteins are exported across the inner and outer membranes in a single step via the type I, type III, type IV or type VI pathways (Tseng et al., 2009). Other proteins are first exported into the periplasmic space via the universal Sec or two-arginine (Tat) pathways and then translocated across the outer membrane via the type II, type V or less commonly, the type I or type IV machinery (Tseng et al., 2009). In Gram-negative fish pathogenic bacteria we can find several examples in which all of these secretion systems, with the exception of the Sec and the general type II pathways, have been related to virulence.

The bacterial twin-arginine translocation system (Tat) is involved in the translocation of proteins in a folded state using a proton gradient as an energy source (Müller, 2005). In $V$. alginolyticus, the Tat pathway plays pleiotropic roles in growth, motility and secretion of some virulent factors such as the extracellular alkaline serine protease (Asp), an important exotoxin in this bacterium as was previously indicated. Fish infection and cytotoxicity assays showed that the Tat system is also required for the virulence of this bacterium in zebra fish and against an epithelioma papulosum cyprinid cell line (He et al., 2011).

The type I or ATP-binding cassette $(\mathrm{ABC})$ transporter pathway exports substrates such as toxins, proteases and lipases (Binet et al., 1997) directly across the inner and outer membranes without periplasmic intermediates. The Yrp1 protease of Y. ruckeri (described in section 3.2.1) is secreted by an $A B C$ protein secretion system composed of three genes termed $y r p D$, yrpE and $y r p F$, and a protease inhibitor inh. Site-directed insertion mutations into the yrpE gene led to the loss of protease activity and attenuation in virulence when bacteria were injected intraperitoneally into rainbow trout (Fernández et al., 2002).

The type III pathway is composed of a complex protein structure spanning both the inner and the outer membranes and it is used exclusively by pathogenic bacteria to deliver virulence factors into host cells, directly interfering with and altering host processes. In fish, two species of the genus Aeromonas (A. salmonicida and A. hydrophila) have been reported to have a functional type III secretion system involved in virulence (Burr et al., 2002; Yu et al., 2004). In A. salmonicida, a mutation in the $a s c V$ gene that encodes an inner membrane component of the type III secretion apparatus results in the lack of toxicity against RTG-2 rainbow trout gonad cells (Burr et al., 2002). In A. hydrophila AH-1, insertional inactivation of two of the type III secretion system genes $(a \circ p B$ and aopD) led to decreased cytotoxicity in carp epithelial cells, increased phagocytosis and reduced virulence in blue gourami (Trichogaster trichopterus Pallas) (Yu et al., 2004). E. tarda also has a type III secretion system that is essential for pathogenesis formed by three genes eseD, eseB and eseC. Infection experiments in fish showed that the eseD mutant exhibited slower proliferation and a 10fold decrease in virulence in fish (Wang et al., 2010a). Finally, in V. alginolyticus, a type III secretion system (T3SS) is required to cause rapid death of infected carp fish cells (Zhao et al., 2010).

The type IV secretion system is related to the transport of macromolecules, such as proteins and DNA. It allows the secretion of nucleoprotein complexes, multi-subunit toxins or monomeric proteins. Recently, this pathway has been divided into two subgroups: type IVa, similar to the VirB secretion system of Agrobacterium tumefaciens and type IVb, assembled from Tra homologues of the Incl Collb-P9 plasmid of Shigella flexneri (Sexton \& Vogel, 2002). Proteins using this pathway can be secreted into the extracellular milieu or directly into a 
host cell. In Y. ruckeri, the traHIJKCLMN operon, which encodes a putative type IVb secretion system, is involved in the virulence of the bacterium (Méndez et al., 2009). LD 50 determinations with rainbow trout fry indicated that a mutation in the traI gene resulted in virulence attenuation. It is suggested that this system contributes to bacterial pathogenicity through the secretion of some effector molecules into the host cells (Méndez et al., 2009).

The type $\mathrm{V}$ secretion system presents the largest family of protein-translocating outer membrane porins in Gram-negative bacteria and the simplest secretion apparatus (Yen et al., 2002). Proteins using this system are translocated across the outer membrane via a transmembrane pore formed by a self-encoded $\beta$-barrel structure. The Pfa1 autotransporter of the fish pathogen $P$. fluorescens is associated with virulence since a mutation in this gene significantly attenuates the virulence of the bacterium and impairs its ability in biofilm production, interaction with host cells, modulation of host immune response and dissemination in host blood (Hu et al., 2009).

The type VI secretion machinery is a recently characterized secretion system that appears to constitute a phage-tail-spike-like injectisome that has the potential to introduce effector proteins directly into the cytoplasm of host cells (Tseng et al., 2009). In E. tarda, a type VI secretion system was identified as EVP (E. tarda virulence protein) gene cluster and consisted of 16 components (evpP-evpO). Compared with the parental strain, in-frame deletion of evpP in E. tarda EIB202 led to a significantly increased $\mathrm{LD}_{50}$ in zebra fish and Japanese flounder, decreased haemolytic activities, failure to adhere to mucus and reduced serum resistance (Wang et al., 2009b). Moreover, the evpP deletion mutant exhibited incapacity to internalize in epithelioma papulosum of carp cell model in vitro, demonstrating that EvpP in type VI secretion machinery plays a critical role in the invasion mechanism of $E$. tarda and merits investigation as a potential target for attenuated live vaccine construction (Wang et al., 2009b).

Finally, different uptake systems such as a cysteine transporter and a zinc transporter were shown to be involved in the ability of Y. ruckeri to infect fish (Dahiya \& Stevenson, 2010a; Méndez et al., 2011).

\section{Endotoxins}

An endotoxin is a toxin which is a structural molecule of Gram-negative bacteria and which is recognized by the immune system of the host. The prototypical examples of endotoxins are complex molecules called lipopolysaccharides (LPS), which are a constituent of the cell wall outer membrane of Gram-negative bacteria. LPS structure consists of three components: an outer polysaccharide region that is highly variable among different bacteria, known as "O antigen", a highly conserved polysaccharide chain called "core" and an inner fatty-acid-rich region known as "lipid A".

Lower vertebrates such as frog and fish are stated to be resistant to endotoxic shock, whereas higher animals are very sensitive to it (Berczi et al., 1966a, 1966b; Wedemeyer et al., 1969). However, in recent years endotoxins/LPS have frequently been shown to be responsible for the pathogenesis of several bacterial fish diseases. The Gram-negative fish pathogens in which endotoxins have been identified as disease-related virulence mechanisms belong mainly to three genera: Aeromonas, Edwardsiella and Vibrio. Gramnegative bacteria have the unique characteristic of smooth and rough variation, which is 
mainly based on the presence or absence of an O-specific chain (Lukácová et al., 2008). The attachment of O-antigen to core lipid-A results in smooth phenotype, while core lipid-A lacking O-antigen is referred to as rough phenotype (Swain et al., 2010). Genes involved in the biosynthesis of the $\mathrm{O}$-antigen have been associated with virulence in different studies. For example, A. hydrophila AH-3 mutants in which the gene that codes for UDP $N$ acetylgalactosamine 4-epimerase (gne) is affected, showed the O- phenotype (LPS without Oantigen molecules) and were less virulent for fish compared to the wild type strain (Canals et al., 2006). The results obtained in a later work (Canals et al., 2007) confirmed that LPS is essential in A. hydrophila pathogenicity. In another study carried out with the same strain, a mutation in galU, a gene that codes for UDP-glucose pyrophosphorylase, caused two types of LPS structures (Vilches et al., 2007). The gall mutation reduced the survival of this strain in serum to less than $1 \%$, decreased the ability to adhere and reduced the virulence of $A$. hydrophila AH-3 in a septicaemia model in fish (Vilches et al., 2007). In a recent work, two rough attenuated variants of $A$. hydrophila, derived from two smooth virulent strains by continuous cultivation in brain-heart infusion agar over a period of 8 years, were discovered to be attenuated, since they produced neither disease nor mortality in the injected fishes (Swain et al., 2010).

In Edwardsiella ictaluri, an LPS O side-chain (O antigen) mutant strain was isolated using transposon mutagenesis (Lawrence et al., 2001). The mutant failed to express O side-chains and was highly attenuated in channel catfish (Ictalurus punctatus) fingerlings compared with the parent wild type strain.

In the virulent strain E. tarda EIB202, a mutation in the gene waaL, which codes for a putative $\mathrm{O}$-antigen ligase, resulted in the absence of O-antigen side chains in the LPS production $(\mathrm{Xu}$ et al., 2010). This waaL mutant was attenuated in virulence, showed an impaired ability in internalization of epithelioma papulosum cyprinid cells and a poor ability to proliferate in vivo. The waaL mutant also exhibited a decreased resistance to serum and polymyxinB and an increased sensitivity to $\mathrm{H}_{2} \mathrm{O}_{2}$, indicating that the LPS was involved in endurance to oxidative stress in hosts during infection. In another study in E. tarda (Wang et al., 2010c), a comparison of pathogenicity of purified LPS and lipid A from virulent and avirulent strains demonstrated that LPS was one of the virulence factors of the E. tarda isolates.

In $V$. vulnificus, there are classically two biotypes with the virulence for eels being specific to strains belonging to biotype 2, a homogeneous LPS-based O serogroup. It was demonstrated that the $\mathrm{O}$ side chain of this LPS determines the selective virulence of biotype 2 for eels (Amaro et al., 1997). In this study, biotype 1 strains were destroyed by the bactericidal action of non-immune eel serum, biotype 2 strains were resistant and rough mutants of biotype 2 lacking the $\mathrm{O}$ polysaccharide side-chain were sensitive and avirulent for eels. Another study in $V$. vulnificus biotype 2 showed that the gne gene is essential for O-antigen biosynthesis and virulence in eels (Valiente et al., 2008). Mutation in gne increased the sensitivity to microcidal peptides, to eel serum and to phagocytosis/opsonophagocytosis. Moreover, significant attenuation of virulence for eels was observed. The change in the attenuatedvirulence phenotype produced by the gne mutation was correlated with the loss of the Oantigen LPS.

In L. anguillarum, the presence of the $\mathrm{O} 1$ antigen side chain was shown to be crucial for the resistance to the bactericidal action of serum from rainbow trout (Welch \& Crosa, 2005). In this work, a mutant in $r m l C$, a gene involved in the biosynthesis of dTDP-rhamnose (a 
common constituent of bacterial LPS O side chains) was isolated. The $r m l C$ mutant was shown to be defective in the production of the $\mathrm{O}$ antigen. In addition to this, a mutant obtained by allelic exchange in $r m l D$, another ORF in the dTDP-rhamnose biosynthetic cluster, showed the same O1-deficient phenotype and was highly attenuated compared to the wild type strain.

\section{Regulation of virulence gene expression}

Pathogenic bacteria are submitted to continuous environmental changes, which may vary significantly during infection process. Therefore, the pathogenicity of the bacteria depends on their ability to survive in stressful environmental conditions. To confront these surrounding variables, bacteria present a complex regulation of gene expression.

\subsection{Two component regulatory system (TCS)}

Bacteria efficiently survive under changeable conditions by utilizing different signal transduction systems. One of the most extended systems is known as the two component regulatory system (TCS) (Gao et al., 2007; Robinson et al., 2000). The typical TCS consists of a sensor kinase that responds to specific signals, phosphorylating the second component of the system (Mitrophanov \& Groisman, 2008). The EsrA-EsrB TCS is well characterized as a virulence regulatory system in E. tarda. Tan et al. (2005) showed that this TCS regulates a type III secretion system related to the pathogenicity of the bacterium. When esr $A$ and esrB genes were disrupted, proteins that compound the type III secretion system (EseB, EseC and EseD) were missing or considerably reduced (Tan et al., 2005). The EsrA-EsrB TCS system also controls other regulator called EsrC. The esrC mutant showed an increase of $50 \%$ in its virulence using blue gourami as the infection model. In this sense, the authors concluded that the EsrC regulator plays an important role in the virulence of $E$. tarda, forming a regulation cascade complex with the TCS EsrA-EsrB, which regulates the expression of the secreted proteins encoded by the type III secretion system and the evp cluster (Zheng et al., 2005). The EsrA-EsrB TCS is also involved in the regulation of the type VI secretion system of E. tarda exercising a positive effect on the transcription of evpP (Wang et al., 2009b). Recently, it has been demonstrated that this EsrA-EsrB TCS governs the expression of EthA haemolysin of $E$. tarda, which belongs to Eth haemolysin system in this bacterium, which comprises EthA and EthB subunits (Wang et al., 2010b).

Another novel TCS is the BarA-UvrY described for Y. ruckeri. In this system, a mutant strain in the response regulator $u v r Y$ gene showed less ability to infect epithelioma papulosum cyprini cells, more sensitivity to $\mathrm{H}_{2} \mathrm{O}_{2}$ and was unable to maintain a high bacterial load in rainbow trout kidney (Dahiya \& Stevenson, 2010b).

\subsection{GntR family regulators}

The GntR regulators are a metabolite-responsive family that represents one of the most abundant groups of Helix-turn-helix $(\mathrm{HTH})$ transcription factors. These proteins contain a characteristic DNA-binding HTH domain at their N-terminus (Hoskisson \& Rigali, 2009). Besides the mentioned regulation system of E. tarda virulence factors, Wang et al. (2009a) have characterized an EthB subunit regulation belonging to the Eth haemolysin system. The $e t h B$ gene encodes the activation/secretion machinery required for the maturation and 
translocation of EthA haemolysin (Hirono et al., 1997). In the study of Wang et al. (2009a), they identified the ethB regulator EthR, a transcription regulator of the GntR family, which controls $e t h B$ expression by direct interaction with the ethB promoter region. Disruption of the regulated expression of ethR significantly decreases bacterial virulence using Japanase flounder as infection model by intraperitoneal injection (Wang et al., 2009a).

\subsection{Sigma factors}

Sigma factors are another type of regulation system. These consist of a class of proteins constituting essential dissociable subunits of prokaryotic RNA polymerase and they are involved in promoter recognition and transcription initiation. These regulation systems are diverse and they have been shown to regulate expression of virulence genes as well as virulence-associated genes (Kazmierczak et al., 2005). Related to the fish pathogenic bacteria, the alternative rpoN sigma factor, classified into the $\sigma^{54}$ subfamily, was proposed as a virulence factor regulator in L. anguillarum. The disruption of the rpoN gene generated an aflagellated mutant, and in consequence, a non-motile strain. The infectivity of $r p o N$ mutant was similar to that of the wild type strain following intraperitoneal injection of fish; however, it was reduced significantly when fish were immersed in bacteria-containing water (O'Toole et al., 1997). The authors concluded that RpoN regulated the expression of the polar flagellum, an important virulence factor, which is necessary during host colonization in the first stages of the water-borne infection ( $\mathrm{O}^{\prime}$ Toole et al., 1997). In $V$. alginolitycus, the alternative rpoS sigma factor has been defined as a virulence factor expression regulator, comprising the extracellular protease activity and cytotoxicity of extracellular products (Tian et al., 2008). In the same way, the authors confirmed the implication of RpoS sigma factor in the regulatory network of the LuxS quorum sensing system; the disruption of rpoS gene showed a decrease of extracellular autoinducer-2 level, involved in the LuxS system (Tian et al., 2008).

\subsection{Quorum sensing}

Bacteria are social organisms that display complex cooperative behaviour, such as conjugation, biofilm formation, antibiotic synthesis, sporulation, secretion of virulence factors and bioluminescence. Many of these kinds of behaviour are regulated by a process known as quorum sensing. Quorum sensing is a cell-to-cell communication system that enables bacteria to synchronize gene expression with population density. The prototype of quorum sensing in Gram-negative bacteria is the LuxI/LuxR circuit of $V$. fischeri (Engebrecht et al., 1983; Fuqua \& Winans, 1994).

In A. hydrophila, the involvement of quorum sensing in pathogenicity could be demonstrated (Bi et al., 2007). In this species, the ahyR gene encodes the LuxR-type response regulator. An ahyR mutant was highly attenuated relative to the wild type strain. The analysis of exoenzyme activity revealed that the ahy $R$ mutant could not produce exoproteases, amylases, haemolysins and Dnases, while the wild type strain of A. hydrophila had a high level of exoenzyme activity. The $S$ layer of $A$. hydrophila could not be detected in the mutant either.

A. salmonicida also possesses the LuxIR-type quorum sensing system, termed AsaIR. It has been shown that the autoinducer synthase AsaI plays a role in the virulence of $A$. salmonicida 
subsp. achromogenes (Schwenteit et al., 2011). A knockout mutant of AsaI did not produce a detectable quorum sensing signal and its virulence in fish was significantly decreased. In addition to this, the expression of two virulence factors (the toxic protease AsaP1 and a cytotoxic factor), was reduced in the mutant. AsaP1 production was also inhibited by synthetic quorum sensing inhibitors.

In E. tarda, it has been suggested that some virulence factors are regulated by the quorum sensing system. An E. tarda strain isolated from deceased flounder was found to produce Nacyl-homoserine-lactones (AHLs) as quorum sensing signal molecules that control the expression of a 55-kDa virulent-strain-specific protein (Morohoshi et al., 2004). In the same bacterium, it has also been shown that the overexpression of EthR, a transcriptional regulator of the GntR family, drastically altered the expression patterns of ethB and $l u x S$ in the host environment during infection, causing vitiation in the tissue dissemination and survival ability of the bacterium, and significant attenuation of the overall bacterial virulence (Wang et al., 2009a). EthR positively modulates $\operatorname{luxS}$ expression and autoinductor AI-2 production by binding to the luxS promoter region (Wang et al., 2009a). In another study (Zhang et al., 2009a), it was found that 5411 and 5906, two small peptides which share sequence identities with the C-terminal of E. tarda LuxS, inhibited AI-2 activity and could vitiate the infectivity of the pathogenic E. tarda strain TX1. The inhibitory effect of 5411 and 5906 on AI-2 activity was proven to be exerted on LuxS, with which these peptides specifically interact. The expression of 5411 and 5906 in TX1 produced effects that are similar to those caused by interruption of LuxS expression, such as the alteration of biofilm production and a decrease in the expression of certain virulence-associated genes. It could also be demonstrated that fish expressing 5411 directly from tissues exhibited enhanced resistance against TX1 infection (Zhang et al., 2009a).

In L. anguillarum, a species known to produce AHLs as quorum sensing signal molecules, the use of furanone C-30, a quorum sensing inhibitor, caused a significant reduction of mortality in rainbow trout during challenge with the bacterium (Rasch et al., 2004). Although neither growth, survival, proteome, motility nor respiration of the bacterium were affected by the concentrations of furanone C-30 used in the challenge experiments, it could not be discounted that the disease suppression effect of furarone C-30 is caused by action directly on the fish defence systems, since it is known that AHLs exert a direct immune modulatory effect on the host. Furthermore, the absence of any clear up or down regulation of $L$. anguillarum proteins would suggest that the furanone is affecting the fish host rather than the quorum sensing system.

In $V$. alginolyticus, it has been shown that the LuxS quorum sensing system plays an important role in regulating the expression of virulence factors (Ye et al., 2008). The luxS mutants of both a standard strain and a fish-clinical isolate had reduced lethality in red seabream (Pagrus major). The two luxS mutants exhibited a lower growth rate and defective flagellar biosynthesis. They also showed a significant decrease in protease production and an increase in both extracellular polysaccharide production and biofilm development. Moreover, in $V$. alginolyticus the LuxO-LuxR regulatory system is involved in the regulation of the exotoxin alkaline serine protease Asp. A LuxR-deficient mutant showed a reduction in asp transcript and the disruption of the luxO gene caused an increase in this virulence factor. Furthermore, the interruption of $l u x O$ resulted in a higher level of $l u x R$ mRNA, indicating that LuxO negatively regulates the expression of $l u x R$, which in turn activates the 
expression of asp (Rui et al., 2009). Recently, Liu et al. (2011) have found that Hfq, an sRNA chaperone, plays an important role in post-translational regulation of the alkaline serine protease Asp, besides other environmental stress responses. The interruption of the $h f q$ gene caused attenuation of virulence in zebra fish and grouper infection models (Liu et al., 2011).

\section{Perspectives and future}

The increasing level of production in the aquaculture industry, in terms of both quantity and the number of fish species cultured, has resulted in the appearance of new bacterial diseases. In this sense, the development of vaccines and diagnostic techniques is probably the major challenge in the field. The study of the biology of fish pathogenic bacteria and in particular, of their virulence factors, is essential in order to achieve these goals. Gene mutation is currently the major and, probably, the best means of determining the involvement of a gene in the pathogenic mechanisms of bacteria. Most of the studies described in this review are based on this fact. However, the relationship between virulence and a particular phenotype as a consequence of gene mutation should be carefully established, since in most cases this alteration produces pleiotropic effects. The recent development of specific and sensitive techniques such as microarrays, genome sequencing, in vivo expression technology, etc. will provide massive information about virulence-related genes as well as their expression and regulation. This will lay the foundations for tackling and solving the infection problems in the aquaculture industry.

\section{References}

Abolghait, S. K., Akeda, Y., Kodama, T., Cantarelli, V. V., Iida, T. \& Honda, T. (2010). Aeromonas hydrophila PepO outer membrane endopeptidase activates human big endothelin-3 in vitro and induces skin ulcer in goldfish (Carassius auratus). Vet Microbiol 145, 113-121.

Allan, B. J. \& Stevenson, R. M. (1981). Extracellular virulence factors of Aeromonas hydrophila in fish infections. Can J Microbiol 27, 1114-1122.

Álvarez, B., Álvarez, J., Menéndez, A. \& Guijarro, J. A. (2008). A mutant in one of two exbD loci of a TonB system in Flavobacterium psychrophilum shows attenuated virulence and confers protection against cold water disease. Microbiology 154, 1144-51.

Amaro, C., Fouz, B., Biosca, E. G., Marco-Noales, E. \& Collado, R. (1997). The lipopolysaccharide $\mathrm{O}$ side chain of Vibrio vulnificus serogroup $\mathrm{E}$ is a virulence determinant for eels. Infect Immun 65, 2475-2479.

Andrews, S. C., Robinson, A. K. \& Rodríguez-Quinones, F. (2003). Bacterial iron homeostasis. FEMS Microbiol Rev 27, 215-37.

Arnadottir, H., Hvanndal, I., Andresdottir, V., Burr, S. E., Frey, J. \& Gudmundsdottir, B. K. (2009). The AsaP1 peptidase of Aeromonas salmonicida subsp. achromogenes is a highly conserved deuterolysin metalloprotease (family M35) and a major virulence factor. J Bacteriol 191, 403-410.

Austin, D. A., Robertson, P. A. W. \& Austin, B. (2003). Recovery of a new biogroup of Yersinia ruckeri from diseased rainbow trout (Onchorynchus mykiss, Walbaum). Syst Appl Microbiol 26, 127-131. 
Bai, F., Sun, B., Woo, N. Y. S. \& Zhang, X.-H. (2010). Vibrio harveyi hemolysin induces ultrastructural changes and apoptosis in flounder (Paralichthys olivaceus) cells. Biochem Biophys Res Commun 395, 70-75.

Berczi, I., Baintner, K., Jr \& Antal, T. (1966a). Comparative assay of endotoxins by oral and parenteral administration. Zentralblatt Veterinarmedizin Reihe B 13, 570-575.

Berczi, I., Bertok, I. \& Bereznai, T. (1966b). Comparative studies on the toxicity of bacterial endotoxins. Annual review of Microbiology 1070-1091.

Bi, Z. X., Liu, Y. J. \& Lu, C. P. (2007). Contribution of AhyR to virulence of Aeromonas hydrophila J-1. Res Vet Sci 83, 150-156.

Binet, R., Létoffé, S., Ghigo, J. M., Delepelaire, P. \& Wandersman, C. (1997). Protein secretion by Gram-negative bacterial ABC exporters--a review. Gene 192, 7-11.

Bjornsdottir, B., Fridjonsson, O. H., Magnusdottir, S., Andresdottir, V., Hreggvidsson, G. O. \& Gudmundsdottir, B. K. (2009). Characterisation of an extracellular vibriolysin of the fish pathogen Moritella viscosa. Vet Microbiol 136, 326-334.

Boyd, J. M., Dacanay, A., Knickle, L. C., Touhami, A., Brown, L. L., Jericho, M. H., Johnson, S. C. \& Reith, M. (2008). Contribution of type IV pili to the virulence of Aeromonas salmonicida subsp. salmonicida in Atlantic salmon (Salmo salar L.). Infect Immun 76, 1445-1455.

Burr, S. E., Stuber, K., Wahli, T. \& Frey, J. (2002). Evidence for a type III secretion system in Aeromonas salmonicida subsp. salmonicida. J Bacteriol 184, 5966-5970.

Butler, A. (2003). Iron acquisition: straight up and on the rocks? Nat Struct Biol 10, 240-1.

Cai, S. H., Wu, Z. H., Jian, J. C. \& Lu, Y. S. (2007). Cloning and expression of gene encoding the thermostable direct hemolysin from Vibrio alginolyticus strain HY9901, the causative agent of vibriosis of crimson snapper (Lutjanus erythopterus). J Appl Microbiol 103, 289-296.

Canals, R., Jiménez, N., Vilches, S., Regué, M., Merino, S. \& Tomás, J. M. (2006). The UDP Nacetylgalactosamine 4-epimerase gene is essential for mesophilic Aeromonas hydrophila serotype O34 virulence. Infect Immun 74, 537-548.

Canals, R., Jiménez, N., Vilches, S., Regué, M., Merino, S. \& Tomás, J. M. (2007). Role of Gne and GalE in the virulence of Aeromonas hydrophila serotype O34. J Bacteriol 189, 540550 .

Cascón, A., Yugueros, J., Temprano, A., Sánchez, M., Hernanz, C., Luengo, J. M. \& Naharro, G. (2000). A major secreted elastase is essential for pathogenicity of Aeromonas hydrophila. Infect Immun 68, 3233-3241.

Chen, Q., Wertheimer, A. M., Tolmasky, M. E. \& Crosa, J. H. (1996). The AngR protein and the siderophore anguibactin positively regulate the expression of iron-transport genes in Vibrio anguillarum. Mol Microbiol 22, 127-34.

Crosa, J. H. (1989). Genetics and molecular biology of siderophore-mediated iron transport in bacteria. Microbiol Rev 53, 517-30.

Crosa, J. H., Hodges, L. L. \& Schiewe, M. H. (1980). Curing of a plasmid is correlated with an attenuation of virulence in the marine fish pathogen Vibrio anguillarum. Infect Immun 27, 897-902.

Dacanay, A., Boyd, J. M., Fast, M. D., Knickle, L. C. \& Reith, M. E. (2010). Aeromonas salmonicida Type I pilus system contributes to host colonization but not invasion. Dis Aquat Org 88, 199-206. 
Dahiya, I. \& Stevenson, R. M. (2010a). The ZnuABC operon is important for Yersinia ruckeri infections of rainbow trout, Onchorynchus mykiss (Walbaum). J Fish Dis 33, 331-340.

Dahiya, I. \& Stevenson, R. M. (2010b). The UvrY response regulator of the BarA-UvrY twocomponent system contributes to Yersinia ruckeri infection of rainbow trout (Onchorynchus mykiss). Arch Microbiol 192, 541-7.

Ellis, A. E., Burrows, A. S. \& Stapleton, K. J. (1988). Lack of relationship between virulence of Aeromonas salmonicida and the putative virulence factors: A-layer, extracellular proteases and extracellular haemolysins. Journal of Fish Diseases 11, 309-323.

Ellis, A. E., Hastings, T. S. \& Munro, A. L. S. (1981). The role of extracellular products in the pathology of furunculosis. Journal of Fish Diseases 4, 41-51.

Engebrecht, J., Nealson, K. \& Silverman, M. (1983). Bacterial bioluminescence: isolation and genetic analysis of functions from Vibrio fischeri. Cell 32, 773-781.

Evenhuis, J. P., Lapatra, S. E., Verner-Jeffreys, D. W., Dalsgaard, I. \& Welch, T. J. (2009). Identification of flagellar motility genes in Yersinia ruckeri by transposon mutagenesis. Appl Environ Microbiol 75, 6630-6633.

Fernández, L., Márquez, I. \& Guijarro, J. A. (2004). Identification of specific in vivo-induced (ivi) genes in Yersinia ruckeri and analysis of ruckerbactin, a catecholate siderophore iron acquisition system. Appl Environ Microbiol 70, 5199-207.

Fernández, L., Prieto, M. \& Guijarro, J. A. (2007). The iron- and temperature-regulated haemolysin YhlA is a virulence factor of Yersinia ruckeri. Microbiology 153, 483-9.

Fernández, L., Secades, P., López, J. R., Márquez, I. \& Guijarro, J. A. (2002). Isolation and analysis of a protease gene with an $\mathrm{ABC}$ transport system in the fish pathogen Yersinia ruckeri: insertional mutagenesis and involvement in virulence. Microbiology 148, 2233-43.

Fouz, B., Barja, J. L., Amaro, C., Rivas, C. \& Toranzo, A. E. (1993). Toxicity of the extracellular products of Vibrio damsela isolated from diseased fish. Current Microbiology 27, 341-347.

Fouz, B., Zarza, C. \& Amaro, C. (2006). First description of non-motile Yersinia ruckeri serovar I strains causing disease in rainbow trout, Onchorynchus mykiss (Walbaum), cultured in Spain. J Fish Dis 29, 339-346.

Fuqua, W. C. \& Winans, S. C. (1994). A LuxR-LuxI type regulatory system activates Agrobacterium $\mathrm{Ti}$ plasmid conjugal transfer in the presence of a plant tumor metabolite. J Bacteriol 176, 2796-2806.

Gao, R., Mack, T. R. \& Stock, A. M. (2007). Bacterial response regulators: versatile regulatory strategies from common domains. Trends Biochem Sci 32, 225-234.

Garduño, R. A., Moore, A. R., Olivier, G., Lizama, A. L., Garduño, E. \& Kay, W. W. (2000). Host cell invasion and intracellular residence by Aeromonas salmonicida: role of the S-layer. Can J Microbiol 46, 660-668.

Gavín, R., Rabaan, A. A., Merino, S., Tomás, J. M., Gryllos, I. \& Shaw, J. G. (2002). Lateral flagella of Aeromonas species are essential for epithelial cell adherence and biofilm formation. Mol Microbiol 43, 383-397.

Genco, C. A. \& Dixon, D. W. (2001). Emerging strategies in microbial haem capture. Mol Microbiol 39, 1-11.

Gunnlaugsdóttir, B. \& Gudmundsdóttir, B. K. (1997). Pathogenicity of atypical Aeromonas salmonicida in Atlantic salmon compared with protease production. J Appl Microbiol $83,542-551$. 
He, H., Wang, Q., Sheng, L., Liu, Q. \& Zhang, Y. (2011). Functional characterization of Vibrio alginolyticus twin-arginine translocation system: its roles in biofilm formation, extracellular protease activity, and virulence towards fish. Curr Microbiol 62, 11931199.

Henrichsen, J. (1972). Bacterial surface translocation: a survey and a classification. Bacteriol Rev 36, 478-503.

Hirono, I., Tange, N. \& Aoki, T. (1997). Iron-regulated haemolysin gene from Edwardsiella tarda. Mol Microbiol 24, 851-856.

Hoskisson, P. A. \& Rigali, S. (2009). Chapter 1: Variation in form and function the helix-turnhelix regulators of the GntR superfamily. Adv Appl Microbiol 69, 1-22.

$\mathrm{Hu}$, Y.-hua, Liu, C.-sheng, Hou, J.-hui \& Sun, L. (2009). Identification, characterization, and molecular application of a virulence-associated autotransporter from a pathogenic Pseudomonas fluorescens strain. Appl Environ Microbiol 75, 4333-4340.

Jia, A., Woo, N. Y. S. \& Zhang, X.-H. (2010). Expression, purification, and characterization of thermolabile hemolysin (TLH) from Vibrio alginolyticus. Dis Aquat Org 90, 121-127.

Kanai, K., and H. Wakabayashi. 1984. Purification and some properties of protease from Aeromonas hydrophila. Bull. Jpn. Soc. Sci. Fish. 50:1367-1374.

Kazmierczak, M. J., Wiedmann, M. \& Boor, K. J. (2005). Alternative sigma factors and their roles in bacterial virulence. Microbiol Mol Biol Rev 69, 527-543.

Khalil, A. H. \& Mansour, E. H. (1997). Toxicity of crude extracellular products of Aeromonas hydrophila in tilapia, Tilapia nilotica. Lett Appl Microbiol 25, 269-273.

Kodama, H., Moustafa, M., Ishiguro, S., Mikami, T. \& Izawa, H. (1984). Extracellular virulence factors of fish Vibrio: relationships between toxic material, hemolysin, and proteolytic enzyme. Am J Vet Res 45, 2203-2207.

Labella, A., Sánchez-Montes, N., Berbel, C., Aparicio, M., Castro, D., Manchado, M. \& Borrego, J. J. (2010). Toxicity of Photobacterium damselae subsp. damselae strains isolated from new cultured marine fish. Dis Aquat Org 92, 31-40.

Lawrence, M. L., Banes, M. M. \& Williams, M. L. (2001). Phenotype and Virulence of a Transposon-Derived Lipopolysaccharide O Side-Chain Mutant Strain of Edwardsiella ictaluri. Journal of Aquatic Animal Health 13, 291-299.

Lemos, M. L., Salinas, P., Toranzo, A. E., Barja, J. L. \& Crosa, J. H. (1988). Chromosomemediated iron uptake system in pathogenic strains of Vibrio anguillarum. J Bacteriol 170, 1920-5.

Leung, K. Y. \& Stevenson, R. M. (1988). Tn5-induced protease-deficient strains of Aeromonas hydrophila with reduced virulence for fish. Infect Immun 56, 2639-2644.

Li, J., Ni, X. D., Liu, Y. J. \& Lu, C. P. (2011). Detection of three virulence genes alt, ahp and aerA in Aeromonas hydrophila and their relationship with actual virulence to zebrafish. J Appl Microbiol 110, 823-830.

Li, W. K., Chen, Y. S., Wann, S. R., Liu, Y. C. \& Tsai, H. C. (2008). Lactococcus garvieae endocarditis with initial presentation of acute cerebral infarction in a healthy immunocompetent man. Intern Med 47, 1143-6.

Liu, H., Wang, Q., Liu, Q., Cao, X., Shi, C. \& Zhang, Y. (2011). Roles of Hfq in the stress adaptation and virulence in fish pathogen Vibrio alginolyticus and its potential application as a target for live attenuated vaccine. Appl Microbiol Biotechnol 91, 353364 . 
Lukácová, M., Barák, I. \& Kazár, J. (2008). Role of structural variations of polysaccharide antigens in the pathogenicity of Gram-negative bacteria. Clin Microbiol Infect 14, 200-206.

Magariños, B., Bonet, R., Romalde, J. L., Martínez, M. J., Congregado, F. \& Toranzo, A. E. (1996). Influence of the capsular layer on the virulence of Pasteurella piscicida for fish. Microb Pathog 21, 289-297.

Masada, C. L., LaPatra, S. E., Morton, A. W. \& Strom, M. S. (2002). An Aeromonas salmonicida type IV pilin is required for virulence in rainbow trout. Dis Aquat Org 51, 13-25.

Mazoy, R., Osorio, C. R., Toranzo, A. E. \& Lemos, M. L. (2003). Isolation of mutants of Vibrio anguillarum defective in haeme utilisation and cloning of $h u v A$, a gene coding for an outer membrane protein involved in the use of haeme as iron source. Arch Microbiol 179, 329-38.

Méndez, J., Fernández, L., Menéndez, A., Reimundo, P., Pérez-Pascual, D., Navais, R. \& Guijarro, J. A. (2009). A chromosomally located traHIJKCLMN operon encoding a putative type IV secretion system is involved in the virulence of Yersinia ruckeri. Appl Environ Microbiol 75, 937-945.

Méndez, J., Reimundo, P., Pérez-Pascual, D., Navais, R., Gómez, E. \& Guijarro, J. A. (2011). A novel $c d s A B$ operon is involved in the uptake of L-cysteine and participates in the pathogenesis of Yersinia ruckeri. J Bacteriol 193, 944-951.

Merino, S., Aguilar, A., Nogueras, M. M., Regue, M., Swift, S. \& Tomás, J. M. (1999). Cloning, sequencing, and role in virulence of two phospholipases (A1 and C) from mesophilic Aeromonas sp. serogroup O:34. Infect Immun 67, 4008-4013.

Merino, S., Aguilar, A., Rubires, X., Abitiu, N., Regué, M. \& Tomás, J. M. (1997a). The role of the capsular polysaccharide of Aeromonas hydrophila serogroup O:34 in the adherence to and invasion of fish cell lines. Res Microbiol 148, 625-631.

Merino, S., Aguilar, A., Rubires, X., Simon-Pujol, D., Congregado, F. \& Tomás, J. M. (1996). The role of the capsular polysaccharide of Aeromonas salmonicida in the adherence and invasion of fish cell lines. FEMS Microbiol Lett 142, 185-189.

Merino, S., Rubires, X., Aguilar, A. \& Tomás, J. M. (1997b). The role of flagella and motility in the adherence and invasion to fish cell lines by Aeromonas hydrophila serogroup O:34 strains. FEMS Microbiol Lett 151, 213-217.

Mitrophanov, A. Y. \& Groisman, E. A. (2008). Signal integration in bacterial two-component regulatory systems. Genes Dev 22, 2601-2611.

Miyoshi, S. \& Shinoda, S. (2000). Microbial metalloproteases and pathogenesis. Microbes Infect 2, 91-8.

Morohoshi, T., Inaba, T., Kato, N., Kanai, K. \& Ikeda, T. (2004). Identification of quorumsensing signal molecules and the LuxRI homologs in fish pathogen Edwardsiella tarda. J Biosci Bioeng 98, 274-281.

Müller, M. (2005). Twin-arginine-specific protein export in Escherichia coli. Res Microbiol 156, 131-136.

Norqvist, A., Norrman, B. \& Wolf-Watz, H. (1990). Identification and characterization of a zinc metalloprotease associated with invasion by the fish pathogen Vibrio anguillarum. Infect Immun 58, 3731-3736.

Ormonde, P., Hörstedt, P., O'Toole, R. \& Milton, D. L. (2000). Role of motility in adherence to and invasion of a fish cell line by Vibrio anguillarum. J Bacteriol 182, 2326-2328. 
Osorio, C. R., Juiz-Rio, S. \& Lemos, M. L. (2006). A siderophore biosynthesis gene cluster from the fish pathogen Photobacterium damselae subsp. piscicida is structurally and functionally related to the Yersinia high-pathogenicity island. Microbiology 152, 3327-41.

Ostland, V. E., Byrne, P. J., Hoover, G. \& Ferguson, H. W. (2000). Necrotic myositis of rainbow trout, Onchorynchus mykiss (Walbaum): proteolytic characteristics of a crude extracellular preparation from Flavobacterium psychrophilum. Journal of Fish Diseases 23, 329-336.

O'Toole, R., Milton, D. L., Hörstedt, P. \& Wolf-Watz, H. (1997). RpoN of the fish pathogen Vibrio (Listonella) anguillarum is essential for flagellum production and virulence by the water-borne but not intraperitoneal route of inoculation. Microbiology (Reading, Engl) 143 ( Pt 12), 3849-3859.

O'Toole, R., Milton, D. L. \& Wolf-Watz, H. (1996). Chemotactic motility is required for invasion of the host by the fish pathogen Vibrio anguillarum. Mol Microbiol 19, 625637.

Pérez-Pascual, D., Gómez, E., Álvarez, B., Méndez, J., Reimundo, P., Navais, R., Duchaud, E. \& Guijarro, J. A. (2011). Comparative analysis and mutation effects of fpp2-fpp1 tandem genes encoding proteolytic extracellular enzymes of Flavobacterium psychrophilum. Microbiology 157, 1196-1204.

Rasch, M., Buch, C., Austin, B., Slierendrecht, W. J., Ekmann, K. S., Larsen, J. L., Johansen, C., Riedel, K., Eberl, L., \& other authors. (2004). An inhibitor of bacterial quorum sensing reduces mortalities caused by Vibriosis in rainbow trout (Onchorynchus mykiss, Walbaum). Syst Appl Microbiol 27, 350-359.

Ratledge, C. (2007). Iron metabolism and infection. Food Nutr Bull 28, S515-23.

Ratledge, C. \& Dover, L. G. (2000). Iron metabolism in pathogenic bacteria. Annu Rev Microbiol 54, 881-941.

Robinson, V. L., Buckler, D. R. \& Stock, A. M. (2000). A tale of two components: a novel kinase and a regulatory switch. Nat Struct Biol 7, 626-633.

Rock, J. L. \& Nelson, D. R. (2006). Identification and characterization of a hemolysin gene cluster in Vibrio anguillarum. Infect Immun 74, 2777-2786.

Rodkhum, C., Hirono, I., Crosa, J. H. \& Aoki, T. (2005). Four novel hemolysin genes of Vibrio anguillarum and their virulence to rainbow trout. Microb Pathog 39, 109-119.

Romalde, J. L. \& Toranzo, A. E. (1993). Pathological activities of Yersinia ruckeri, the enteric redmouth (ERM) bacterium. FEMS Microbiol Lett 112, 291-299.

Rowe, G. E. \& Welch, R. A. (1994). Assays of hemolytic toxins. Meth Enzymol 235, 657-667.

Rui, H., Liu, Q., Wang, Q., Ma, Y., Liu, H., Shi, C. \& Zhang, Y. (2009). Role of alkaline serine protease, asp, in Vibrio alginolyticus virulence and regulation of its expression by luxO-luxR regulatory system. J Microbiol Biotechnol 19, 431-438.

Sakai, D. K. (1985). Loss of virulence in a protease-deficient mutant of Aeromonas salmonicida. Infect Immun 48, 146-152.

Salinas, P. C., Tolmasky, M. E. \& Crosa, J. H. (1989). Regulation of the iron uptake system in Vibrio anguillarum: evidence for a cooperative effect between two transcriptional activators. Proc Natl Acad Sci U S A 86, 3529-33.

Santos, Y., Laixier, R., Bandin, I., Lamas, J. \& Toranzo, A. E. (1991). Susceptibility of turbot (Scophthalmus maximus), coho salmon (Oncorhynchus kisutch), and rainbow trout (O. 
mykiss) to strains of Vibrio anguillarum and their exotoxins. Journal of Applied Ichthyology 7, 160-167.

Santos, Y., Toranzo, A. E., Barja, J. L., Nieto, T. P. \& Villa, T. G. (1988). Virulence properties and enterotoxin production of Aeromonas strains isolated from fish. Infect Immun 56, 3285-3293.

Schwenteit, J., Gram, L., Nielsen, K. F., Fridjonsson, O. H., Bornscheuer, U. T., Givskov, M. \& Gudmundsdottir, B. K. (2011). Quorum sensing in Aeromonas salmonicida subsp. achromogenes and the effect of the autoinducer synthase AsaI on bacterial virulence. Vet Microbiol 147, 389-397.

Sexton, J. A. \& Vogel, J. P. (2002). Type IVB secretion by intracellular pathogens. Traffic 3, 178-185.

Stork, M., Di Lorenzo, M., Mourino, S., Osorio, C. R., Lemos, M. L. \& Crosa, J. H. (2004). Two tonB systems function in iron transport in Vibrio anguillarum, but only one is essential for virulence. Infect Immun 72, 7326-9.

Sun, B., Zhang, X.-H., Tang, X., Wang, S., Zhong, Y., Chen, J. \& Austin, B. (2007). A single residue change in Vibrio harveyi hemolysin results in the loss of phospholipase and hemolytic activities and pathogenicity for turbot (Scophthalmus maximus). J Bacteriol $189,2575-2579$.

Suomalainen, L.-R., Tiirola, M. \& Valtonen, E. T. (2006). Chondroitin AC lyase activity is related to virulence of fish pathogenic Flavobacterium columnare. J Fish Dis 29, 757763.

Swain, P., Behera, T., Mohapatra, D., Nanda, P. K., Nayak, S. K., Meher, P. K. \& Das, B. K. (2010). Derivation of rough attenuated variants from smooth virulent Aeromonas hydrophila and their immunogenicity in fish. Vaccine 28, 4626-4631.

Tan, Y. P., Zheng, J., Tung, S. L., Rosenshine, I. \& Leung, K. Y. (2005). Role of type III secretion in Edwardsiella tarda virulence. Microbiology (Reading, Engl) 151, 2301-2313.

Tian, Y., Wang, Q., Liu, Q., Ma, Y., Cao, X. \& Zhang, Y. (2008). Role of RpoS in stress survival, synthesis of extracellular autoinducer 2, and virulence in Vibrio alginolyticus. Arch Microbiol 190, 585-594.

Tong, Y. \& Guo, M. (2009). Bacterial heme-transport proteins and their heme-coordination modes. Arch Biochem Biophys 481, 1-15.

Toranzo, A. E. \& Barja, J. L. (1993). Virulence factors of bacteria pathogenic for coldwater fish. Annual Review of Fish Diseases 3, 5-36.

Tseng, T.-T., Tyler, B. M. \& Setubal, J. C. (2009). Protein secretion systems in bacterial-host associations, and their description in the Gene Ontology. BMC Microbiol 9 Suppl 1, S2.

Valiente, E., Padrós, F., Lamas, J., Llorens, A. \& Amaro, C. (2008). Microbial and histopathological study of the vibriosis caused by Vibrio vulnificus serovar E in eels: the metalloprotease Vvp is not an essential lesional factor. Microb Pathog 45, 386393.

Vilches, S., Canals, R., Wilhelms, M., Saló, M. T., Knirel, Y. A., Vinogradov, E., Merino, S. \& Tomás, J. M. (2007). Mesophilic Aeromonas UDP-glucose pyrophosphorylase (GalU) mutants show two types of lipopolysaccharide structures and reduced virulence. Microbiology (Reading, Engl) 153, 2393-2404. 
Vipond, R., Bricknell, I. R., Durant, E., Bowden, T. J., Ellis, A. E., Smith, M. \& MacIntyre, S. (1998). Defined deletion mutants demonstrate that the major secreted toxins are not essential for the virulence of Aeromonas salmonicida. Infect Immun 66, 1990-1998.

Wandersman, C. \& Delepelaire, P. (2004). Bacterial iron sources: from siderophores to hemophores. Annu Rev Microbiol 58, 611-47.

Wang, B., Mo, Z. L., Xiao, P., Li, J., Zou, Y. X., Hao, B. \& Li, G. Y. (2010a). EseD, a putative T3SS translocon component of Edwardsiella tarda, contributes to virulence in fish and is a candidate for vaccine development. Mar Biotechnol 12, 678-685.

Wang, F., Zhang, M., Hu, Y. Z, Zhang, W. W \& Sun, L. (2009a). Regulation of the Edwardsiella tarda hemolysin gene and luxS by EthR. J Microbiol Biotechnol 19, 765773.

Wang, Q., Liu, Q., Cao, X., Yang, M. \& Zhang, Y. (2008). Characterization of two TonB systems in marine fish pathogen Vibrio alginolyticus: their roles in iron utilization and virulence. Arch Microbiol 190, 595-603.

Wang, X., Wang, Q., Xiao, J., Liu, Q., Wu, H., Xu, L. \& Zhang, Y. (2009b). Edwardsiella tarda T6SS component evpP is regulated by esrB and iron, and plays essential roles in the invasion of fish. Fish Shellfish Immunol 27, 469-477.

Wang, X., Wang, Q., Xiao, J., Liu, Q., Wu, H. \& Zhang, Y. (2010b). Hemolysin EthA in Edwardsiella tarda is essential for fish invasion in vivo and in vitro and regulated by two-component system EsrA-EsrB and nucleoid protein HhaEt. Fish Shellfish Immunol 29, 1082-1091.

Wang, Y., Zhang, X. H. \& Austin, B. (2010c). Comparative analysis of the phenotypic characteristics of high- and low-virulent strains of Edwardsiella tarda. J Fish Dis 33, 985-994.

Wedemeyer, G., Ross, A. J. \& Smith, L. (1969). Some Metabolic Effects of Bacterial Endotoxins in Salmonid Fishes. Journal of the Fisheries Research Board of Canada 26, 115-122.

Welch, T. J. \& Crosa, J. H. (2005). Novel role of the lipopolysaccharide O1 side chain in ferric siderophore transport and virulence of Vibrio anguillarum. Infect Immun 73, 58645872.

Wertheimer, A. M., Verweij, W., Chen, Q., Crosa, L. M., Nagasawa, M., Tolmasky, M. E., Actis, L. A. \& Crosa, J. H. (1999). Characterization of the angR gene of Vibrio anguillarum: essential role in virulence. Infect Immun 67, 6496-6509.

Xu, L., Wang, Q., Xiao, J., Liu, Q., Wang, X., Chen, T. \& Zhang, Y. (2010). Characterization of Edwardsiella tarda waaL: roles in lipopolysaccharide biosynthesis, stress adaptation, and virulence toward fish. Arch Microbiol 192, 1039-1047.

Xu, Z., Wang, Y., Han, Y., Chen, J. \& Zhang, X.-H. (2011). Mutation of a novel virulencerelated gene mltD in Vibrio anguillarum enhances lethality in zebra fish. Res Microbiol 162, 144-150.

Yang, H., Chen, J., Yang, G., Zhang, X.-H. \& Li, Y. (2007). Mutational analysis of the zinc metalloprotease EmpA of Vibrio anguillarum. FEMS Microbiol Lett 267, 56-63.

Ye, J., Ma, Y., Liu, Q., Zhao, D. L., Wang, Q. Y. \& Zhang, Y. X. (2008). Regulation of Vibrio alginolyticus virulence by the LuxS -sensing system. J Fish Dis 31, 161-169.

Yen, M. R., Peabody, C. R., Partovi, S. M., Zhai, Y., Tseng, Y. H. \& Saier, M. H. (2002). Protein-translocating outer membrane porins of Gram-negative bacteria. Biochim Biophys Acta 1562, 6-31. 
Yu, H. B., Rao, P. S. S., Lee, H. C., Vilches, S., Merino, S., Tomas, J. M. \& Leung, K. Y. (2004). A type III secretion system is required for Aeromonas hydrophila AH-1 pathogenesis. Infect Immun 72, 1248-1256.

Zhang, M., Jiao, X. D., Hu, Y. H. \& Sun, L. (2009a). Attenuation of Edwardsiella tarda virulence by small peptides that interfere with LuxS/autoinducer type 2 sensing. Appl Environ Microbiol 75, 3882-3890.

Zhang, W. W., Hu, Y. H., Wang, H. L. \& Sun, L. (2009b). Identification and characterization of a virulence-associated protease from a pathogenic Pseudomonas fluorescens strain. Vet Microbiol 139, 183-188.

Zhao, Z., Chen, C., Hu, C.-Q., Ren, C.-H., Zhao, J.-J., Zhang, L.-P., Jiang, X., Luo, P. \& Wang, Q.-B. (2010). The type III secretion system of Vibrio alginolyticus induces rapid apoptosis, cell rounding and osmotic lysis of fish cells. Microbiology (Reading, Engl) 156, 2864-2872.

Zheng, J., Tung, S. L. \& Leung, K. Y. (2005). Regulation of a type III and a putative secretion system in Edwardsiella tarda by EsrC is under the control of a two-component system, EsrA-EsrB. Infect Immun 73, 4127-4137.

Zhong, Y., Zhang, X.-H., Chen, J., Chi, Z., Sun, B., Li, Y. \& Austin, B. (2006). Overexpression, purification, characterization, and pathogenicity of Vibrio harveyi hemolysin $\mathrm{VHH}$. Infect Immun 74, 6001-6005. 


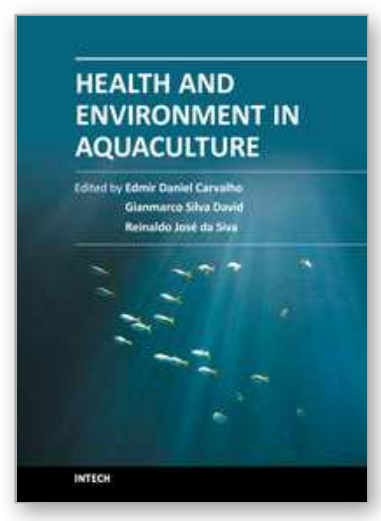

\author{
Health and Environment in Aquaculture \\ Edited by Dr. Edmir Carvalho
}

ISBN 978-953-51-0497-1

Hard cover, 414 pages

Publisher InTech

Published online 11, April, 2012

Published in print edition April, 2012

Aquaculture has been expanding in a fast rate, and further development should rely on the assimilation of scientific knowledge of diverse areas such as molecular and cellular biology, and ecology. Understanding the relation between farmed species and their pathogens and parasites, and this relation to environment is a great challenge. Scientific community is involved in building a model for aquaculture that does not harm ecosystems and provides a reliable source of healthy seafood. This book features contributions from renowned international authors, presenting high quality scientific chapters addressing key issues for effective health management of cultured aquatic animals. Available for open internet access, this book is an effort to reach the broadest diffusion of knowledge useful for both academic and productive sector.

\title{
How to reference
}

In order to correctly reference this scholarly work, feel free to copy and paste the following:

Jessica Méndez, Pilar Reimundo, David Pérez-Pascual, Roberto Navais, Esther Gómez, Desirée Cascales and José A. Guijarro (2012). An Overview of Virulence-Associated Factors of Gram-Negative Fish Pathogenic Bacteria, Health and Environment in Aquaculture, Dr. Edmir Carvalho (Ed.), ISBN: 978-953-51-0497-1, InTech, Available from: http://www.intechopen.com/books/health-and-environment-in-aquaculture/an-overview-onvirulence-associated-factors-of-gram-negative-fish-pathogenic-bacteria

\section{INTECH}

open science | open minds

\author{
InTech Europe \\ University Campus STeP Ri \\ Slavka Krautzeka 83/A \\ 51000 Rijeka, Croatia \\ Phone: +385 (51) 770447 \\ Fax: +385 (51) 686166 \\ www.intechopen.com
}

\author{
InTech China \\ Unit 405, Office Block, Hotel Equatorial Shanghai \\ No.65, Yan An Road (West), Shanghai, 200040, China \\ 中国上海市延安西路 65 号上海国际贵都大饭店办公楼 405 单元 \\ Phone: +86-21-62489820 \\ Fax: +86-21-62489821
}


(C) 2012 The Author(s). Licensee IntechOpen. This is an open access article distributed under the terms of the Creative Commons Attribution 3.0 License, which permits unrestricted use, distribution, and reproduction in any medium, provided the original work is properly cited. 